\section{Density Inversions in Canadian Eastern Arctic Waters}

Among the hydrographic results of the Calanus expeditions of 1949-51 in Ungava Bay, Hudson Strait and Frobisher Bay, sponsored by the Fisheries Research Board of Canada, are twenty-two instances of density inversion showing unstable conditions in the sea. They were observed at twenty stations (two stations showing inversion at two different depths) out of a total of forty-eight stations occupied during the three seasons. Six of the inversion stations were in Ungava Bay, one in the Button Islands north of Cape Chidley, four in Hudson Strait between Wakeham Bay and Lake Harbour, and the remainder in Frobisher Bay.

Such instabilities, appearing in oceanographic results in the past, have usually been looked upon as fictitious, and attributed to errors in thermometer readings, sample labelling, titration or filing of results. In the present instance, titrations have been repeated where possible, and the methods used on board ship seem to preclude the possibility of other errors. Recently, Spilhaus et al. ${ }^{1}$ have recorded similar inversions in the waters just south of Cape Cod, and have given evidence of some correlation of the times of observed instability with the times of lunar transit. I am informed by Dr. Carsola (personal communication) that inversions of short duration are common in shallow-water observations in progress at the U.S. Navy Electronics Laboratory at San Diego, and Dr. John Tait, of Aberdeen, has reported (at the 1952 meeting of the Conseil Permanent in Copenhagen) some more or less persistent instabilities observed during work in the Faero-Shetland Channel. There is a published record of another example, in the Okhotsk Sea, from the nineteenth century ${ }^{2}$, and the Michael Sars expedition of 1910 found a density inversion at one station in the Atlantic $\left(28^{\circ} 37^{\prime} \mathrm{N}\right.$.; $\left.19^{\circ} 08^{\prime} \mathrm{W}.\right)^{3}$.

The Calanus observations have been related to the state of the tide in each instance and are plotted on a tidal clock in Fig. 1. Tests $\left(\chi^{2}\right)$ comparing the radial scatter of the stations with inversions, those without, and of all stations, respectively, with an equally distributed radial pattern, give the $P$ values shown. The latter two observed distributions are reasonably close to a random scatter, as would be expected; but the distribution of the instabilities verges on disagreement with random scatter, and the

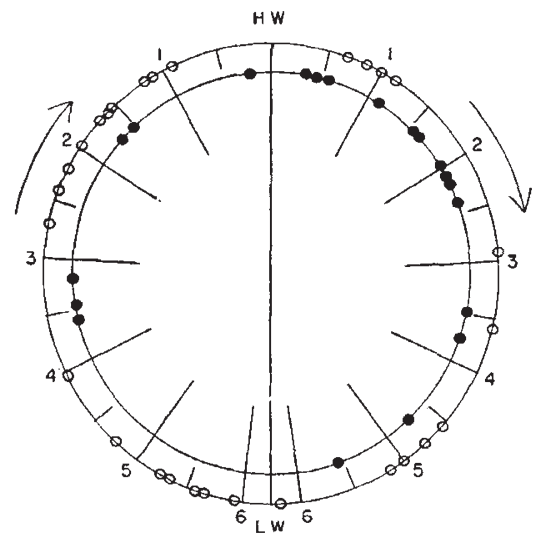

Fig. 1. A twelve $\frac{1}{2}$-hour tidal clock, showing the times, with Fig. 1. A twect to tide, at which stations with density inversions (black circles) and without density inversions (open circles) were occupied. The $P$ values are explained in the text: $P, P=0.065$
O, $P=0.345 ;+0, P=0.565 ; S . E \cdot P=0.055$
$P$ value for the comparison of the means (standard error of the difference of the means) of the inversion and non-inversion stations is on the margin of significant disassociation (difference is 2.02 times its standard error). It is, moreover, at once apparent on examination that, of the twenty inversion stations, half lie in one quadrant, in the first three hours of the ebb tide.

The establishment of these unstable conditions, even for the short periods of time during which they probably exist, obviously requires considerable forces, which are apparently to be found in the extreme tidal movements of the area. Hudson Strait tides are very high (33 ft. at Ashe Inlet), the mean spring tide interval at Frobisher Bay is $32 \frac{1}{2} \mathrm{ft}$., and a tide of more than $50 \mathrm{ft}$. has recently been recorded at the head of Ungava Bay.

The details of this work will appear in full in due course.

Eastern Arctic Investigations,

Fisheries Research Board of Canada, and Department of Zoology, McGill University, Montreal. April 6.

1 Spilhaus, A. F., Ehrlich, A., and Miller, A. R., Trans. Amer. Geophys. Union, 31 (2), 213 (1950)

Makaroff, S., "Le 'Vitiaz' et L'Ocean Pacifique" (St. Petersburg, 1894).

s Sverdrup, H. U., Johnson, Martin W., and Fleming, Richard H.

"The Oceans", 417 (Prentice-Hall, Inc., New York, 1942).

\section{Temperature-Ranges and Distributions. of some Vascular Plants}

Artempts to fit isotherms to certain limits of areas of plant distributions have sometimes been successful ; but, for example, in the discussion of the areas given in the Biological Flora of the British Isles, only rarely is an isotherm limit shown. A July isotherm is given as an upper temperature limit for Lobelia dortmanna ${ }^{1}$, and a July or August isotherm as a lower limit for Halimione portulacoides ${ }^{2}$, and a January isotherm as a lower limit for Arbutus unedo ; and in addition to these and some other examples in the literature, I notice that the January (actual) isotherm $35^{\circ} \mathrm{F}$. gives an approximate fit for the southern limit of Andro. meda polifolia. The fact of a broad coincidence between an isotherm and a limit of a distribution does not prove a relationship, but nevertheless a reasonable fit has usually been taken as indicating that temperature may probably be the limiting factor.

A limit of winter cold will obviously operate on a plant in a different way from a limit of July heat; and four possible sorts of temperature limits have been quoted above for particular cases. It could be supposed that for each plant species there may be, in broad terms, an optimum summer temperature, with upper and lower limits (beyond which the species is either damaged or else is at a disadvantage in competition with other species better adapted to the particular temperature-levels), and an optimum winter temperature, with upper and lower limits. Winter limits might be expected to operate most typically at the month of lowest temperature (as an approximation, January in the northern hemisphere); and although July might not always be the most operative summer month, in long-term means, deviations of adjacent months would at least be approximate functions of July deviations.

It does not, however, seem to have been generally realized how frequently plant areas can be represented 